positions and are concentrated in a narrower range of occupations than white people and in low paid jobs. ${ }^{5}$ When regional health authorities consult voluntary organisations they are usually from the "traditional white" voluntary sector. $^{3}$ If people from ethnic minorities are recruited they may feel marginalised or isolated. They want to be recruited on merit and not as a token gesture to ensure a "black face" on the board.

Equality Across the Board comes up with nearly 30 recommendations to ensure that recruitment to NHS boards is more equitable. The report is adamant that the lead must come from ministers, who should issue written guidance to regional health authorities on recruitment practices and consult the chairperson of these authorities about setting recruitment goals. Closer to home, ministers should look at the composition of the NHS Policy Board and the NHS Management Executive-neither includes anyone from an ethnic minority. Employing people from ethnic minorities in senior positions in the NHS gives a clear signal that the NHS values their contribution and can offer a good career path to able and well qualified young people from ethnic minorities.

Ministers should establish a "corporate race initiative," a high profile unit that looks at all issues related to race in the NHS, from board membership to employment and the provision of services, says the report. To be effective the people working in the unit would need to have adequate power and resources. Ideally the person leading the initiative should report directly to the chief executive of the NHS Management Executive and be on the NHS Management
Executive's board. The initiative should advise ministers on appointment procedures for non-executive members and advise authorities and trusts on implementing fair recruitment procedures. The report says that it should make links with various ethnic minority organisations and implement programmes of positive action for people from ethnic minorities such as fast track management courses. Health authorities and trusts should produce job descriptions for jobs at board level and advertise them in the black press.

Equality Across the Board comes on the heels of the government's proposals to steamline the management structure of the NHS. ${ }^{6}$ It seems inevitable that the number of NHS boards will fall. Some members of the working party are worried that as competition for places on boards intensifies the Department of Health may forget about its goal and that members of ethnic minorities, rather than being actively recruited, could be squeezed out altogether. It's up to the ministers to ensure that this does not happen.

LUISA DILLNER Assistant editor

$B M \mathcal{F}$

1 Owen D. Ethnic minorities in Great Britain: settlement pattern. Warwick: Centre for Research in Ethnic
Relations, University of Warwick, 1992. (1991 census statistical paper No 1.)
2 Jewson N, Mason D, Bourke H, Bracebridge C, Brosnan F, Milton K. Changes in ethnic minority
membership of health authorities 1989-92. BMF 1993;307:604-5.
3 NAHAT, King's Fund Centre. Equality across the board. London: King's Fund Centre, 1993 .
4 Public Appointments Unit. Public bodies 1992. London: Cabinet Office, 1993.
5 Office of Population Censuses and Surveys. Labour force survey 1990 and 1991. London: HMSO,
1992 .
6 Department of Health. Managing the new NHS. London: HMSO, 1993 .

\title{
Publishing the results of sponsored clinical research
}

\author{
They are public, not private, property
}

Progress in science and medicine depends not only on research but also on its publication, dissemination, and evaluation and thoughtful integration with existing knowledge. One important obstacle to the process is secrecy, as Alick Munro points out on $\mathrm{p} 1340 .{ }^{1}$ Pharmaceutical companies and some other sponsors of clinical research-for example, certain government departments - tend to think that because they have paid for a piece of work they own it and are entitled to decide what should be published and in what form. This view ignores the rights of the participants in the study, ${ }^{2}$ the investigators, and the organisations or institutions in which the work has been done.

Heather Waldron and Ron Cookson (p 1331) touch on some of these concerns in relation to sponsored multicentre studies in general practice, but they do not address them directly. ${ }^{3}$ General practitioners who take part in such studies usually have little influence on their design, interpretation, or publication, though Waldron and Cookson describe how a formal research group can facilitate learning and promote greater involvement.

But there may be a risk that a research group of general practitioners depending totally on one company, however friendly and ethical, might become less rigorously critical of that company, and building up loyalty to a company in this way could overlap uncomfortably with marketing activities. A research group of general practitioners should ideally be an equal partner working with several companies and perhaps other organisations. It should be able to get data analysed independently of sponsoring companies and to make its own decisions on publication. Reports of trrials from such inde- pendent groups of general practitioners should preferably be completely free from commercial considerations.

A report on drug information by the World Health Organisation has recommended that pharmaceutical companies should make available all information, published and unpublished, on the studies conducted for obtaining a product licence as well as those initiated after licensing; it has also recommended that governments should require the results of all pivotal studies of a drug to be accessible to interested parties after the drug has been marketed. ${ }^{4}$ Now that London has been chosen as the site for the European Medicines Evaluation Agency the government should consider reintroducing the Medicines Information Bill, ${ }^{5}$ which it scuttled so disgracefully earlier this year.

Underreporting of research must be regarded as a form of scientific misconduct because it distorts the publicly available evidence. ${ }^{6}$ It is waste of the resources used in the unreported work (patients' cooperation, investigators' skill, health facilities, time, and money), and otherwise avoidable later research is necessary to correct the distortions. Investigators, sponsors, and research ethics committees should all try to minimise underreporting. The development of electronic journals, which can publish work fast and have unlimited space, is removing one important barrier to the publication of good trials.

Even if at present not all clinical trials can be published, the findings of all must be made accessible to anyone wishing to review trials concerned with a particular problem. The first step would be to make it possible to obtain a complete list of the unpublished as well as the published trials and the names 
and addresses of the people who have information about them. The newly established Cochrane Centre in Baltimore, in collaboration with the United States National Institutes of Health, is coordinating the creation of a register of randomised controlled trials, which will be as comprehensive as possible. ${ }^{7}$ The international Cochrane Collaboration hopes that pharmaceutical companies will contribute details of all randomised controlled trials that they have sponsored to this register. Most companies would gain little real commercial advantage by keeping old results under wraps, but all would benefit from access to the whole range of previous work sponsored by the industry.

A simple way of achieving comprehensive access to trial data in the future would be to enter all clinical trials in a register at inception. ${ }^{8}$ Such registers already exist for trials in some areas of medicine, and more are needed. In Britain the information strategy that is part of the NHS Research and Development Programme envisages a register of all research projects undertaken in the NHS. The regional directors of research and development will be responsible for creating and maintaining the register, perhaps with the help of the local research ethics committees. In the United States a similar initiative is being considered by the National Institutes of Health.

ANDREW HERXHEIMER Consultant

UK Cochrane Centre,

NHS Research and Development Programme, Oxford OX2 7LG

1 Munro AJ. Publishing the findings of clinical research. BMf 1993;307:1340-1.

2 Herxheimer A. The rights of the patient in clinical research. Lancet 1988;ii:1128-30.

3 Waldron HA, Cookson RF. Avoiding the pitfalls of sponsored multicentre research in general practice. BMF 1993;307:1331-4.

4 World Health Organisation, Regional Office for Europe. Drug information. Report on a meeting, Madrid, October 1991. Copenhagen: WHO, 1992 (EUR/CP/DSE 168.)

5 Medawar C. Drugs, secrecy, and society. $B M F$ 1993;306:81-2.

6 Chalmers I. Underreporting research is scientific misconduct. $¥ A M A$ 1990;263:1405-8.

7 Chalmers I, Dickersin K, Chalmers TC. Getting to grips with Archie Cochrane's agenda. BMf 1992;305:786-8.

8 Making clinical trialists register. Lancet 1991;338:244.

\title{
Managing stroke: the way forward
}

\author{
Organised stroke care saves lives
}

The greatest recent leap forward in managing stroke has not been a novel neuroprotective agent or a better method of imaging ischaemic brain but the (distinctly less glamorous) publication of a formal overview showing that organised stroke care saves lives.

Over the past decade a series of randomised trials have compared organised stroke care (mainly in stroke units or by stroke teams) with routine care (usually in general medical wards). Each trial suggested that a systematic approach to the care of patients with acute stroke led to better short term and long term outcome, though none was large enough to convince on its own. A formal statistical overview of these trials has clarified the position substantially: organised stroke care significantly reduced early death by more than a quarter. Long term mortality was also significantly reduced (the odds of death at 12 months was $21 \%$ lower in patients in stroke units). ${ }^{1}$ Preliminary analyses of the effects on dependency at about six months after stroke, the need for long term institutional care, and the length of hospital stay also suggested that organised care provided in the acute phase of stroke produced better results than routine management (P Langhorne, personal communication).

These results have important implications for health care providers. Several of the more recent trials were conducted in Scandinavian countries, and, perhaps unsurprisingly, doctors and hospital administrators in these countries had started to set up stroke units and organised systems of stroke care even before the results of this overview were published. For example, in Norway most district general hospitals now have a stroke unit or some organised system of stroke care ( $P$ Sandset, personal communication). Other developed countries are following suit at varying speeds.

Which of the many components of an organised system of stroke care could have led to the improved outcome has been vigorously debated, and there is no consensus on what constitutes an "ideal" stroke unit. Larger, multicentre trials testing individual parts of the system of care will be needed to dissect out which components contribute most to the benefits and which are the most cost effective.

Difficulties with funding have been evident from the early 1980s. The first stroke units were often set up-quite expensively - with a research grant or substantial funding from the hospital, and at the end of the research grant (or when their special funding ran out) many units succumbed to financial pressures.

Any organised stroke service must be sustainable. Any hospital wanting to set up a stroke service should begin by reviewing how patients with stroke are currently managed and how much this routine care costs. A service can often be established by reorganisation of what already exists without costing much more. Currently in Britain, partly as a result of the publication of The Health of the Nation, authorities purchasing health care are paying much greater attention to stroke services, which will undoubtedly stimulate the provision of better stroke care in British hospitals. Quite reasonably, purchasers will also be looking for cost effective stroke services; the current data strongly suggest effectiveness, but more data will be needed to clarify cost effectiveness.

In contrast to the clear evidence that organised stroke care saves lives, no convincing evidence has emerged from randomised trials that any specific form of medical treatment is effective in the acute phase of stroke. ${ }^{2}$ Fortunately, there are now many randomised trials testing different forms of medical treatment.

As ischaemic stroke accounts for about four out of five strokes most of the trials are focusing on strategies to reduce the damaging effects of cerebral ischaemia. All treatments have a common goal in this respect-to reduce the volume of brain damaged by ischaemia, thereby reducing the degree of neurological impairment. Less neurological deficit should lead to fewer early deaths and, more importantly, less disability and handicap in survivors.

The most dramatic way of achieving this could be with thrombolytic treatment for early cerebral reperfusion. An overview of the existing trials suggested that this treatment was promising but might have substantial hazards too. ${ }^{3}$ Several moderately sized randomised trials of fibrinolytic treatment (mainly with streptokinase or tissue plasminogen activator) in the acute phase of ischaemic stroke are now under way in Europe, Australia, and North America. Antithrombotic treatment (with aspirin or heparin, or both), though simpler and probably less risky, is much more widely 